\title{
A POTENCIALIDADE DO PENSAMENTO DE BOAVENTURA SANTOS PARA OS ESTUDOS ORGANIZACIONAIS
}

\section{Boaventura Santos' thoughts potencial for organizational studies}

\section{Ana Lúcia Medeiros}

Doutora em Administração de Empresas na

Universidade Presbiteriana Mackenzie.

Professora da Universidade Federal do Tocantins. Palmas, TO. Brasil. e-mail:analucia@uft.edu.br

\section{Maria Luisa Mendes Teixeira}

Doutora em Administração pela Universidade de São Paulo e pós-doutorado pela Universidad Complutense de Madrid. Professora da Universidade Presbiteriana Mackenzie. São Paulo, SP. Brasil. e-mail:malluluisa@gmail.com

\section{RESUMO}

O artigo discute a potencialidade do pensamento de Boaventura Santos para os estudos organizacionais. Suas ideias são consideradas contra-hegemônicas, uma vez que não só fazem crítica ao paradigma científico dominante, como apontam alternativas epistêmicas para que se tenha outra compreensão da realidade. No que tange à potencialidade do pensamento de Boaventura Santos, acredita-se que, assim como Habermas, Foucault e Derrida servem de referência para os estudos críticos organizacionais as desse autor poderão também dar contribuições para os estudos organizacionais. A superação da lógica das monoculturas é um importante passo em direção a um novo caminho a ser seguido pelas organizações. Identificar e credibilizar os diferentes saberes presentes nas práticas sociais e nas práticas de gestão são caminhos que podem fazer com que as relações sociais estabelecidas no interior das organizações sejam pautadas por saberes contra-hegemônicos.

Palavras-chave: Monocultura. Sociologia das ausências. Sociologias das emergências. Contra-hegemônica.

\section{ABSTRACT}

This study discusses the potential of Boaventura Santos' thoughts concerning the organizational studies, which are considered counter-hegemonic, once they not only criticize the mainstream scientific paradigm, but also point out epistemic alternatives aiming to achieve a different understanding of reality. Apropos the ideas of Boaventura Santos potential - as well as Habernas, Foucault and Derrida are references to the organizational critique studies, it is believed that - the author's studies can also contribute to the organizational studies. The logical overcoming of monocultures is an important step towards a new path to be followed by organizations. Identifying and giving credit to different knowledge existing in the social and management practices can ease the social relations established into the organizations in order to have them guided by counter-hegemonic knowledge.

Keywords: Monoculture. Sociology of absences. Sociology of emergency. Counter-hegemonic. 


\section{INTRODUÇÃO}

As organizações enquanto produtoras de bens e serviços encarregam-se da geração de renda e do produto da economia (HARVEY, 2010; ADLER, 2009). No ato da produção, entram em cena o processo de produção e o processo de trabalho, os quais se inserem nas relações sociais desenvolvidas em seu interior com o propósito de alcançar determinadas finalidades e resultados.

Analisando a gênese das organizações, sua história e os estudos sobre elas realizados, nota-se que os estudos organizacionais receberam uma forte influência do paradigma funcionalista, que tem como base a epistemologia positivista com caráter universalista e determinista que vê a organização como um ente coisificado, orientado por uma racionalidade objetivista e quantitativa, constituindo-se em um corpo a-histórico e a-político (MATITZ; VIZEU, 2012). Todavia, nas últimas décadas, há um entendimento de que as organizações são constituídas por relações e interações sociais que as tornam complexas, ultrapassando a concepção de homo economicus para concebê-lo como homo social (MOZZATO; GRZYBOVSKI, 2013). Os estudos organizacionais ancorados em teorias funcionalistas têm recebido críticas por parte de pesquisadores que partem do pressuposto de que os fenômenos devem ser singularizados ao invés de coisificados, universalizados ou predeterminados (DAVEL; VERGARA, 2001) como, por exemplo: Abdalla, Faria, (2017); Alcadipane e Tureta (2009), Bertero, Caldas e Wood Jr. (1999), Davel e Alcadipani (2002), Kopelke e Boeira (2016), Meneguetti e Faria (2012), Misockzky (2010), Paes de Paula (2007), Paes e Dellagnelo (2012a, 2012b); Schlickmann e Melo (2009), Serva (2013, 2017). Os críticos compreendem as organizações como um ambiente social onde se faz presente o poder na tomada de decisão, conflitos nas relações de práticas de gestão autoritárias que estão associados a contextos históricos, políticos, culturais e sociais, mostrando, portanto, que a compreensão do mundo organizacional requer abordagens que suplantem a lógica positivista (BARROS; CARRIERI, 2015; MISOCZKY; ANDRADE, 2005; VIZEU, 2010). Segundo Paes de Paula e Alcadipani (2004), essa nova grelha teórica é caracterizada por três aspectos fundamentais: visão desnaturalizada da administração, intenções desvinculadas de desempenho e busca de emancipação. Nessa perspectiva, surgem os estudos organizacionais críticos que perpassam por várias linhas teóricas - teoria crítica incluindo as três gerações: Escola de Frankfurt, a liderada por Habermas e, por último a linha seguida por Axel Honneth -, a teoria crítica em estudos organizacionais, a corrente que atua na critical management studies e por último as análises críticas em estudos organizacionais (FARIA, 2009).

Os pensadores que se utilizam da teoria crítica para analisar as organizações "acreditam que as formas de organização do mundo contemporâneo só podem ser compreendidas como resultados de um processo histórico em todas as suas instâncias" (FARIA, 2008, p. 28). Por isso, há a necessidade de olhar com atenção para os fenômenos relacionados às consequências do controle do trabalho pelo capital e à sua exploração entre tantas outras questões.

A teoria crítica em estudos organizacionais se baseia em Marx e busca estuda-las observando a centralidade do trabalho, os processos e as relações de trabalho que culminam na exploração do trabalho pelo capital onde o objetivo maior é a maximização do lucro. Nesta perspectiva teórica compreende-se que o trabalhador é um sujeito alienado e sua força de trabalho é comprada como mercadoria para ser usada no processo produtivo das organizações (FARIA, 2008, 2009; MOZZATO; GRZYBOVSKI, 2013). A linha do critical management studies foi difundida na Europa e nos Estados Unidos e trata de estudos da gestão e está ancorada em uma base epistemológica pós-estruturalista que restringe a amplitude das possibilidades emancipatórias (PAES DE PAULA; MARANHÃO; BARROS, 2009; FARIA, 2009). Por último, análises críticas em estudos organizacionais abraça um campo amplo de teorias, tendo como referência estudos como o pós-estruturalismo de Foucault, o pós-modernismo de Lyotard, as análises institucionais de Lourau e Lapassade, o simbolismo de Bourdieu, o imaginário de Castoriadis entre outros que estudam as organizações, sob a perspectiva das relações de poder (FARIA, 2009).

Em que pese que os estudos do grupo colonialidade/modernidade não estejam dentro da classificação feita por Faria (2009), esta vertente teórica está ganhando relevância no campo dos estudos 
organizacionais críticos. A corrente teórica que se debruça sobre as questões de hegemonia e contra hegemonia trazidas pela ciência eurocentrista, busca compreender a sociedade a partir dos confrontos entre culturas e da relação de subordinação dos que foram colonizados pelos países hegemônicos e ditos "civilizados". Esse processo não somente gerou genocídio em outras formas de saberes e de direitos, como criou uma linha abissal entre o sul e o norte global (SANTOS, 2009, 2010b). No Brasil, neste campo de estudo, destacam-se os trabalhos de Abdalla e Faria (2017), Rosa e Alcadipani (2013), Wood Jr., Tonelli e Cooke (2011). O marco teórico utilizado nestes trabalhos foi o pensamento latino-americano liderado pelos membros do grupo colonialidade/modernidade que criaram uma nova epistemologia orientada pelo pensamento crítico fronteiriço. As referências teóricas nesta área que orientam os estudiosos brasileiros são: Walter Mignolo, Enrique Dussel, Anibal Quijano e Ramón Grosfoguel, Wallerstein, Castro-Gomes, Maldonado-Torres, Lander,Arthuro Escobar, Coronil, Walsh Boaventura Santos e Zulma Palermo (BALESTRIN, 2013).

Este ensaio tem como objetivo apresentar a potencialidade do pensamento de Boaventura Santos para os estudos organizacionais como uma perspectiva crítica ao pensamento hegemônico e como uma alternativa para compreendê-las a partir das categorias sociológicas das ausências, das emergências e do trabalho de tradução. Se propõe também a avançar nas reflexões sobre a potencialidade do pensamento de Boaventura Santos para os estudos organizacionais anteriormente oferecidas por autores como Juncklaus, Bini e Moreto Neto (2016), Paes e Dellagnelo (2012a, 2012b), Barcellos e Dellagnelo (2013) e Souza (2016).

$\mathrm{O}$ artigo está dividido em três seções, além da introdução e das considerações finais. Na primeira seção, apresenta-se o pensamento hegemônico como o norte. Na segunda, faz-se uma discussão sobre a linha de pensamento do Boaventura Santos e a construção de um paradigma emergente. Na terceira, apresenta-se a perspectiva teórica de Boaventura Santos e sua potencialidade para os estudos organizacionais.

\section{O PENSAMENTO HEGEMÔNICO COMO O (N)ORTE?}

A história da ciência mostra que, ao longo dos anos, o conhecimento científico foi capaz de gerar progresso nos mais diversos campos do conhecimento, mas, pari passu, gerou déficits que se materializaram na forma de violência, da destruição do ecossistema e da miséria absoluta em algumas partes do planeta.

A epistemologia positivista é a forma de conhecimento que preside a ciência moderna desde o século XVII. Além disso, é pautada pela totalidade que se constituiu em um modelo hegemônico de conhecimento altamente dependente da racionalidade técnica (MORIN, 2011; SANTOS, 2010b). Esse modelo que sustentou a produção do conhecimento nos últimos séculos foi o responsável pela morte de qualquer outra forma de saber e de conhecimento e, por isso, é visto como o paradigma científico dominante (SANTOS, 2007, 2009, 2010b). A hegemonia desse paradigma colocou sobre seus pés uma concepção epistemológica positivista cujas ideias fundamentais se assentavam nos seguintes postulados:

Distinção entre sujeito e objeto e entre natureza e sociedade ou cultura; redução da complexidade do mundo a leis simples susceptíveis de formulação matemática; uma concepção da realidade dominada pelo mecanismo determinista e da verdade como representação transparente da realidade; uma separação absoluta entre conhecimento científico - considerado o único válido e rigoroso - e outras formas de conhecimentos como o senso comum ou estudos humanísticos; privilegiamento da causalidade funcional, hostil à investigação das causas últimas, consideradas metafísicas, e centrada na manipulação e transformação da realidade estudada pela ciência (SANTOS, 2010b, p. 25).

É fato que as organizações são analisadas por diferentes paradigmas científicos, todavia ainda é o funcionalista o de maior notoriedade no campo das ciências administrativas. Autores, como Donaldson (1997) mencionam que “(..) aquele núcleo de conceitos funcionalistas é bastante razoável, tanto conceitual quanto filosoficamente" (BURRELL, 2007, p. 437). Desde as últimas décadas, a reboque de concepções epistemológicas não-positivistas, novas lentes começaram a ser utilizadas para observar e analisar fenômenos organizacionais a partir de diversos 
paradigmas cujas teorias passaram a ser referências nesse campo de conhecimento. No campo da teoria crítica destacam-se Hockheimer, Adorno, Marcuse, Benjamim, Fromm e Habermas, além de estudos críticos com vertente teórica marxista (FARIA, 2008, 2009; MISOCZKY, 2010). A vertente pós-estruturalista é ainda pouco explorada quando empregada para estudar as organizações brasileiras, porém, os autores mais citados como referência são: Foucault, Derrida, Baumam, Deleuze, Lyotard e Jameson (SOUZA, 2012). Há outro campo teórico dentro dos estudos organizacionais cuja vertente teórica é a histórica, e, no Brasil, existem vários trabalhos publicados, destacando-se: Barros e Carrieri (2015), Costa, Barros e Martins (2010), Matitz e Vizeu (2012), Vizeu (2010).

Por último, chama-se a atenção para a perspectiva teórica que se ancora na colonialidade/ modernidade que coloca a lente sobre a crítica ao pensamento hegemônico, especialmente no caso das organizações, onde se questiona sobre os saberes e práticas de gestão importadas dos Estados Unidos e dos países anglo-saxônicos. Chama-se a atenção para a produção das ausências que são produzidas no interior das organizações a partir dos saberes hegemônicos que são introjetados como o norte a ser seguido, sem qualquer reflexão acerca do que somos, considerando-nos à margem dos processos e técnicas administrativas. (BARROS, CARRIERI, 2015; WANDERLEY; BARROS, 2018; MACHADO; TEIXEIRA, 2016; MEDEIROS; TEIXEIRA, 2017; PAES; DELLAGNELO, 2012a, 2012b; BARCELLOS; DELLAGNELO, 2013; SOUZA, 2016).

\section{BOAVENTURA SANTOS E A CONSTRUÇÃO DE UM PARADIGMA EMERGENTE}

Quando observamos o Brasil sobre a perspectiva econômica, política e social, percebemos o quanto a cultura colonialista influenciou as organizações e as instituições brasileiras (ROSA; ALCADIPANI, 2013; MOTTA, 2014).

Ao trazer à baila o pensamento de Boaventura Santos (1995, 2005c 2007, 2009, 2010b), para os estudos organizacionais, em que pese ser autor de origem portuguesa, busca-se apresentar uma nova lente para observar a realidade das organizações. A sua obra é uma crítica ao paradigma moderno positivista e, lança o olhar sobre uma nova forma de fazer ciência. Em seus estudos, reafirma que o mundo está vivendo uma transição paradigmática (SANTOS, 1995; 2005b; 2007; 2009; 2010b). Mostra que se faz necessário uma epistemologia que tenha um pensamento alternativo às alternativas e não apenas apresentar soluções para problemas que, na sua visão, já não são mais modernos. Portanto, para problemas não modernos, são necessárias soluções não modernas (SANTOS, 2009, 2010a)

A epistemologia positivista, colonialista como premissa, resultou em exclusão social e destruição do meio ambiente, assim, esses déficits são resultados da lógica cujo objetivo principal tem de ser a produção de riqueza e a maximização do lucro. Em seu livro, a introdução a uma ciência pós-moderna, Boaventura Santos (2010b) chama a atenção para a necessidade de emergir um novo paradigma que leve em consideração não apenas a prudência científica, mas, que se coloque em relevo as questões sociais, a decência da vida. A ciência deve-se colocar em função não apenas do conhecimento prudente, mas também, sobretudo, que torne a vida decente (SANTOS, 2009, 2010a). Esses novos conhecimentos são necessários para reduzir os déficits produzidos pelo pensamento dominante.

$\mathrm{O}$ autor fala em ruptura epistemológica por compreender que o paradigma positivista hegemônico não dá conta de explicar os problemas que não se configuram mais como as grandes narrativas, e, desse modo, as soluções dadas não respondem ao que está posto. No entanto, Boaventura Santos também menciona que o fazer científico na perspectiva que vai além do positivismo deve buscar uma nova epistemologia, sem o revanchismo que negue o que já existe: a ciência moderna. É necessário avançar e procurar novas formas de conhecimento, sem que seja necessário um rompimento abrupto com a epistemologia vigente (SANTOS, 1995, p. 53), o que remete ao conceito de demarcação da ciência, em vez de ruptura conforme define Stengers (2002). De acordo com essa autora, a ruptura procede quando uma diferença entre o antes e o depois é estabelecida, descredibilizando o que existia. A demarcação da ciência, por sua vez, considera ser possível que as 
diversas ciências falem diferentes linguagens, que, entretanto, se comunicam no plano da historicidade em que estão inseridas.

Boaventura Santos acredita ser possível pensar um mundo que, ao invés de separar os saberes, possibilite uni-los. Para isso, é importante transcender à epistemologia da ciência moderna para que, seja possível ir rumo a uma racionalidade mais ampla e que esteja de acordo com as necessidades de hoje. Para Boaventura Santos, há, na matriz da modernidade ocidental, dois modelos que trazem em si dois tipos de conhecimento distintos: o conhecimento de regulação e o de emancipação. Quanto a esse último, é o que se mostra mais adequado ao paradigma emergente, uma vez que "o conhecimento-emancipação deve ser construído a partir da relação entre o respeito à igualdade e o respeito às diferenças" (SANTOS, 2007, p. 62). Essa nova forma de "conhecer" aspira a uma nova psicologia, a uma nova construção da subjetividade, pois "não basta criar um novo conhecimento, é preciso que alguém se reconheça nele" (SANTOS, 2005b, p. 333).

Esse autorreconhecimento pode ser necessário para que os sujeitos busquem também novas formas de viver, de trabalhar, de gerir e de fazer ciência. Esse novo jeito de fazer as coisas deveria ser realizado pelo viés da emancipação e da dignidade humana, dado que um conhecimento emancipatório e digno destaca a relação entre o respeito à igualdade e ao reconhecimento das diferenças, aos direitos e aos deveres dos seres humanos (SANTOS, 2007). Quando Boaventura Santos destaca a ideia de se produzir um conhecimento emancipatório, está defendendo, portanto, que uma sociedade emancipada e digna é aquela que respeita as pessoas e suas idiossincrasias. Aqui se apresenta, então, o âmago do pensamento de Boaventura Santos: para compreender a realidade, que é multifacetada, também é necessário entender que os processos são incompletos, bem como os saberes e, igualmente, a própria cultura.

É por isso que Boaventura Santos (2007, 2009, 2010a) aponta a necessidade de uma nova epistemologia para ajudar a compreender o mundo, isso porque existe uma riqueza social que "está a ser desperdiçada” (SANTOS, 2010a, p. 94). É para evitar esse desperdício de experiências que a ecologia dos saberes $^{1}$, do tempo, da escala, das diferenças e da produção se apresentam como alternativa, enquanto um "conjunto de epistemologias que parte da possibilidade de diversidade e da globalização contra-hegemônica e pretendem contribuir para as credibilizar e fortalecer" (SANTOS, 2010a, p. 154).

Um conceito chave no pensamento de Boaventura Santos é o termo razão indolente, que é o ponto de partida para fazer a crítica ao paradigma dominante - racionalidade ocidental e positivista. É a partir dessa crítica que se pode dimensionar que, ao longo dos séculos, o positivismo não conseguiu produzir conhecimento suficiente para dar respostas aos problemas que se avizinhavam em decorrência da própria evolução das relações sociais. Segundo Boaventura Santos (2010b) a experiência social em todo o mundo é muito maior e mais complexa do que a racionalidade moderna entende e apresenta como relevante. A compreensão do mundo está relacionada com a questão das temporalidades e, por último, a característica fundamental desse paradigma traduz-se no fato de contrair o presente e ampliar o futuro. Portanto, o fundamento da crítica de Boaventura Santos ao paradigma dominante - razão indolente - é o entendimento de que ela se assenta na razão impotente, arrogante, metonímica e proléptica. Nas palavras do autor:

\begin{abstract}
A razão impotente é aquela que não exerce porque pensa que nada pode fazer contra uma necessidade concebida como exterior a ela própria. A razão arrogante, não sente necessidade de exercer-se porque se imagina incondicionalmente livre e, por conseguinte, livre da necessidade de demonstrar a sua própria liberdade. A razão metonímica que se reivindica como a única forma de racionalidade. A razão proléptica não se aplica a pensar o futuro, porque julga que sabe tudo a respeito dele e o concebe como uma superação linear do presente (SANTOS, 2010b, p. 95).
\end{abstract}

As razões que dão sustentação ao paradigma dominante se cristalizaram nas formas de determinismo/realismo, livre-arbítrio/construtivismo, a parte tomada pelo todo e pelo domínio da natureza (SANTOS, 2007). A razão metonímica (primazia do todo sobre as partes) e a proléptica (o futuro é uma orientação para o progresso determinado pelo

A ecologia de saberes é um conjunto de epistemologias que se contrapõe ao pensamento moderno ou hegemônico que é norteado pelas monoculturas. (SANTOS, 2010a) 
presente a partir de uma concepção de tempo linear) são as formas que melhor evidenciam as principais categorias do positivismo. Como entende o paradigma dominante e visivelmente esgotado para refletir sobre as novas realidades sociais, Boaventura Santos propõe outro mundo e, para isso, lança mão de três pressupostos metassociológicos: a sociologia das ausências, a sociologia das emergências e o trabalho de tradução.

Com a sociologia das ausências, o autor procura dar voz ao que a razão metonímica traduz como não existente, ou seja, "transformar objetos impossíveis em possíveis e com base neles transformar as ausências em presenças" (SANTOS, 2010a, p. 102). Na sociologia das emergências, busca-se apontar alternativas que cabem no horizonte das possibilidades concretas, pois com ela se "produzem experiências possíveis, que não estão dadas porque não existem alternativas para isso, mas são possíveis e já existem como emergência" (SANTOS, 2007, p. 38). Quanto ao trabalho de tradução, o autor busca criar inteligibilidade entre os saberes, gerando, com isso, o interconhecimento (SANTOS, 2009, 2010c). Em uma sociedade multicultural e complexa, faz-se necessário usar do artifício da tradução e da hermenêutica diatópica com vistas a ampliar a compreensão das diferentes realidades sociais.

As ausências e as emergências podem ser encontradas na sociedade em seus mais diversos espaços, desde o espaço do conhecimento, da produção, do trabalho, do reconhecimento, da comunicação e da democracia, entre outros. Para evidenciá-las, faz-se necessário o trabalho da tradução para se produzir interconhecimento (SANTOS, 2007). Segundo Boaventura Santos (2009), a sociedade se organiza em espaços estruturais, que são localizações sedimentadas de unidades de ação (estado, nação, sistema capitalista, sociedade de consumo, cidadania), e uma ação desencadeia uma prática social, que é "sempre uma constelação de algumas ou de todas as diferentes formas de ação" (SANTOS, 2009, p. 309).

As ações podem ser individuais e coletivas e são realizadas em diferentes espaços estruturais, que, como tais, são unidades de práticas sociais, e estas, se assentam no contexto histórico e social e incluem o que se fala e o que se dá como pressuposto.
A linguagem, os instrumentos, os documentos, as imagens, os símbolos, os papéis definidos, os procedimentos codificados, as normas e os contratos que as diversas práticas exigem para os fins específicos são todos incluídos como práticas. Além delas, incluem aí também todas as relações implícitas, as convenções tácitas, os pequenos sinais, as normas escritas, as intuições reconhecíveis, as percepções específicas, as sensibilidades sintonizadas, os entendimentos consagrados, os pressupostos subjacentes e as noções compartilhadas da realidade (WENGER, 2001). As práticas sociais fruto de relações sociais, de interações individuais, coletivas e grupais ocorrem em diferentes espaços estruturais, entre eles o espaço da produção, os quais constituem as organizações.

\section{POTENCIALIDADE DO PENSAMENTO DE BOAVENTURA SANTOS PARA OS ESTUDOS ORGANIZACIONAIS}

A organização é também uma unidade de ação e de prática social, logo, neste trabalho, compreende-se que as práticas de gestão são aquelas que nascem das relações e das interações sociais e que são mediadas, de alguma maneira, pelo exercício do poder e pela regulamentação do direito do trabalho.

Segundo Boaventura Santos (2009), o que faz de uma relação social um exercício de poder é a intensidade com que são desigualmente tratados os interessados que compartilham uma mesma relação, ou seja, o grau em que um grupo afeta o outro de maneira inversa aos interesses do último. As organizações na sociedade capitalista se apresentam por meio de uma estrutura hierárquica ou de uma classificação social, "as sociedades capitalistas são formações ou constelações políticas, constituídas por seis modos básicos de produção e de poder que se articulam de maneiras específicas (SANTOS, 2009, p. 272).

Essa articulação se dá em seis espaços estruturais que geram também seis formas de poder, que são: no espaço doméstico, a forma de poder é o patriarcado; no espaço da produção, é exploração; no espaço do mercado, é o fetichismo da mercadoria; no espaço da comunidade, é a diferenciação desigual entre quem pertence ou não à comunidade; no 
espaço da cidadania, é a dominação; e, no espaço do mundo, é o intercâmbio desigual (SANTOS, 2005a, 2005b, 2007, 2009).

A relação entre os espaços mundo e de produção é recíproca e pode ser vista sob a ótica do processo de acumulação de capital. Esse processo é caracterizado por desigualdades nas relações de produção e na produção pela distribuição desigual da mais-valia responsável pelas hierarquias que se perpetuam no mundo (SANTOS, 2009). Boaventura Santos (2009) destaca que existe uma dinâmica de desenvolvimento entre os espaços da produção e do mundo que é simbiótica e recíproca e, ainda, que no momento em que esses espaços se consolidam, enquanto constelações sociais, podem reforçar o processo de globalização hegemônica, caracteristicamente marcada por exploração e desigualdade.

As monoculturas do saber, das escalas dominantes, da produtividade mercantil e do trabalho que orientam as organizações produtivas são responsáveis pela degradação não somente dos recursos naturais, mas também pela deterioração das relações humanas que se fazem presentes e necessárias nos processos de trabalho e de produção. Esse processo se encarregou de produzir ausências ao silenciar os saberes alternativos e os direitos daqueles diretamente envolvidos nas práticas sociais das organizações (SANTOS, 2007). O homem centrado e dotado de racionalidade absoluta impõe suas regras e seus saberes por meio do poder que ele dispõe - político, econômico, social - àqueles que são dominados e explorados. Assim, pois, se constituiu o pensamento monocultural e colonialista que transpôs barreiras geográficas e ocidentalizou toda a forma de conhecimento.

Para superar esse processo, é necessário caminhar em outras direções e estabelecer relações sociais no espaço da produção e mundo que, ao invés de dominação, seja de solidariedade e de respeito e, ainda, que ao invés de ser orientada para a destruição do meio ambiente e das relações domésticas, seja focada na construção de um novo mundo que tenha como tônica a construção de uma política emancipatória de direitos humanos, de emancipação e de dignidade.

Ao criticar as monoculturas que orientam todo um modo de ver uma dada realidade social, Boaventura Santos propõe como pensamento alternativo a possibilidade de construção da emancipação a partir de uma nova relação entre o respeito à igualdade e o princípio do reconhecimento da diferença. Aqui está um princípio: o respeito à capacidade que os indivíduos têm de ter direitos (SANTOS, 2009, 2010a). Para que esse ideal defendido possa produzir a emancipação aqui relatada, as relações sociais relativas às práticas de gestão em organizações devem ser permeadas pelos princípios da igualdade e do reconhecimento das diferenças e que, com isso, busquem garantir a dignidade humana nas organizações, a inclusão social e a autodeterminação para que possam potencializar as interações entre os indivíduos nos seus mais diversos espaços (SANTOS, 2009).

A partir dessa concepção, acredita-se que as formas de poder concebidas da visão da razão metonímica poderão ceder espaço para maneiras alternativas do exercício do poder. No espaço da produção, o poder é exercido por meio da exploração e amparado juridicamente pelo direito da produção. Nas organizações, o saber que orienta a forma de sua organização é aquele associado ao produtivismo, ao tecnologismo, à formação profissional e à cultura empresarial (SANTOS, 2009). Ao associarmos a forma de poder com as normas que regem as relações produtivas e com o que se entende sobre forma epistemológica de se pensar a produção das organizações, temos elementos suficientes para indicar que as práticas de gestão produzem ausências de dignidade e de emancipação humana.

Essa compreensão pode ser feita não pela perspectiva de analisar o que existe, pela produção do que é visível, do que é aparente, mas por uma lente que consiga captar a produção das não existências, do invisível e das ausências. Por esse caminho será possível encontrar meios alternativos para se fazer gestão numa perspectiva contra-hegemônica, sem negligenciar a função específica das organizações, que é a produção de mercadorias para atender às necessidades da sociedade.

A força do pensamento de Boaventura Santos pode ser uma contribuição para mostrar que as organizações, enquanto espaço de produção, possam ser capazes não apenas de dar visibilidade às ausências que são refletidas nas práticas de gestão, mas também de fomentar as emergências que podem ser evidenciadas nas mesmas práticas. Para isso, será necessário compreender que há múltiplas e diversas experiências 
que são possíveis e podem ser exploradas, como a adoção de um modelo de gestão orientado pelo reconhecimento dos saberes e dos direitos de todos os envolvidos em todas as esferas do processo de produção de mercadorias. Nesse sentido, sugere-se que as experiências diárias sejam valorizadas, e que a amplitude do presente seja dilatado em face das expectativas que são criadas para o futuro, ou seja, muito das vivências do presente são perdidas porque vive-se em busca de um progresso que se espera em um tempo futuro. Assim, as ausências produzidas nas organizações ocorrem não somente por meio da monocultura produtivista que busca a eficiência e o lucro, mas, também, pela monocultura do tempo linear, pelo rigor científico e pela escala de classificação social. Essas três monoculturas produzem ausências por não reconhecer outros saberes de gestão senão os hegemônicos, por estabelecer hierarquias e ordenamentos sociais por meio de diferenciações salariais entre homens e mulheres, pretos e brancos, "produtivos" e "improdutivos" e por não encontrar outras formas de experenciar o tempo.

Entende-se, portanto, que a perspectiva apontada por Boaventura Santos tem potencialidade para os estudos organizacionais porque as categorias sociológicas utilizadas em sua teoria dão conta de explicar os fatos da realidade das organizações, a exemplo, das ausências produzidas pelos saberes de gestão importados. Além disso, há que se colocar em discussão as questões culturais que são observadas por boa parte dos estudos organizacionais como categorias dicotômicas. Para o autor, há que se respeitar as diferenças quando estas as inferiorizam e respeitar a igualdade quando esta as diferenciam.

Outro aspecto que nos permite defender a potencialidade do pensamento de Boaventura Santos diz respeito a possibilidade de se ter um modelo de gestão ancorado nas ecologias dos saberes que parte da possibilidade da diversidade e do reconhecimento da igualdade e das diferenças dos trabalhadores e dos capitalistas. Essas ecologias assumiriam os espaços das monoculturas, e as práticas de gestão que estariam centradas nas relações entre saberes, nas hierarquias e nos poderes que se geram entre eles e, com isso, seria possível criar relações horizontais, o que superaria a monocultura da escala dominante, e, por conseguinte, a arquitetura organizacional das empresas cujas estruturas são verticalizadas. Acredita-se que o pensamento de Boaventura Santos acrescenta aos estudos uma nova perspectiva de como deveriam ser as relações humanas no interior das organizações, e, não se defende aqui uma ideia vaga de humanização da forma como é tratada pela literatura behaviorista, e, tão pouco como um pensamento utópico.

Quando introduzimos os conceitos de ausências, emergências e ecologias dos saberes como um conjunto de epistemologias que, se implantadas, podem ser capazes de modificar as relações humanas que se cristalizaram nas práticas de gestão. Por fim, vislumbra-se também que uma nova organização poderá emergir a partir do momento em que as práticas de gestão e sociais se apresentarem como dignas e emancipatórias.

Os trabalhos de pesquisadores brasileiros que utilizaram Boaventura Santos para os estudos organizacionais apontam-no como uma alternativa às estruturas que não estão inseridas no modelo hegemônico, mas que estão na periferia do sistema capitalista de produção, como por exemplo, a economia solidária, a gestão social de cooperativas e autogestão de pequenos empreendimentos (PAES; DAGNELLO, 2012a, 2012b; BARCELLOS; DAGNELLO, 2013).

$\mathrm{O}$ que está sendo posto aqui pode contribuir para os estudos organizacionais como uma perspectiva de transformação dos saberes de gestão hegemônica, a partir do momento em que contribui para discutir as ausências de dignidade e de emancipação que são produzidas pelas práticas de gestão delineadas pelo paradigma funcionalista.

É possível expandir as categorias sociológicas apresentadas pelo filósofo quando se discute a necessidade de se ter uma gestão participativa onde as linhas que estabelecem as relações de poder e que se materializam nos organogramas das organizações, sejam de conexão de saberes, de troca de saberes e de experiências do presente, por isso a necessidade de expandir o presente e contrair o futuro. Acredita-se que pensar novos saberes de gestão poderia trazer reflexões para a emergência de uma transformação social onde o trabalho não seria encarado como uma condenação a quem é obrigado a fazê-lo. Com essa nova perspectiva, o trabalhador não seria condenado, segundo a mitologia grega, a ser sisifo que foi julgado por Zeus a rolar uma pedra montanha acima, monta- 
nha abaixo sem que isso fizesse qualquer sentido para a sua vida, a não ser o cumprimento de uma tarefa em troca de um valor qualquer para a sua subsistência.

A ruptura com as monoculturas apresentadas pelo autor, especialmente, a do rigor cientifico daria lugar a uma ecologia de saberes, a da escala de classificação social daria lugar a uma estrutura organizacional menos hierarquizada, classificada, ordenada, onde abriria-se espaço para respeitar a diversidade - que é fato da realidade social - dentro das organizações, seja por meio da equiparação salarial e pela ocupação dos cargos decisórios, onde fosse possível construir a emancipação a partir de uma nova relação entre o respeito da igualdade e o princípio do reconhecimento da diferença que vai de encontro a linha hegemônico. Boaventura Santos, apesar de ser europeu, compõe um grupo de pesquisadores que constitui o pensamento crítico de fronteira que é encabeçado por latinos americanos, hispânicos, indianos e até americanos, conforme já citado neste trabalho.

Assim como precisamos de uma consciência crítica para compreender o mundo, se faz necessário, também, usá-la para analisar as organizações que por anos são orientadas por lógicas produtivistas e que aprisionam as subjetividades dos trabalhadores, sequestrando deles a capacidade de pensar e agir como sujeito emancipado. Os saberes de gestão na perspectiva funcionalista e hegemônicos prejudicam o mundo organizacional e o conjunto da vida social (MOZZATO; GRZYBOVSKY, 2013).

\section{CONSIDERAÇÕES FINAIS}

O que se reitera aqui é que o pensamento de Boaventura Santos apresenta pressupostos teóricos capazes de apontar alternativas para a compreensão dos fenômenos organizacionais. Considerando que o campo de análise é vasto e apostando que há muito a ser conhecido no que tange às questões organizacionais, o que foi delineado a partir da posição teórica do autor é uma possibilidade substanciada que pode dar ainda mais densidade aos estudos de natureza crítica. Como esse pensador apresenta uma construção teórica contra-hegemônica, isso o torna ainda mais necessário para analisar os fenômenos organizacionais, sobretudo porque, mesmo na atualidade, os paradig- mas que procuram compreender a organização foram disseminados por pensadores naturais das nações que detêm a hegemonia do pensamento científico e do poder econômico (RODRIGUES; CARRIERI, 2001).

É bom deixar claro que aqui que o objetivo é apontar a potencialidade do pensamento de Boaventura Santos para os estudos organizacionais e que este possa trazer à baila a concepção de novos saberes de gestão. O que se defende aqui, é que as práticas de gestão e sociais consubstanciadas a partir dos pressupostos das sociologias das ausências e das emergências e do conjunto de epistemologias das ecologias de saberes possam contribuir para o alargamento do campo de estudo, colocando em evidência a necessidade de trazer para o debate um olhar para além das dicotomias que ainda se usam nos estudos organizacionais.

Nesse sentido, este trabalho reforça a abertura para que se incluam novos teóricos no campo dos estudos organizacionais e que pesquisas possam ser realizadas em organizações para que seja possível observar a produção de ausências e de emergências que ocorrem por meio das relações humanas e de práticas gerenciais orientadas pelo paradigma hegemônico.

Entende-se, portanto, que é possível compreender as organizações a partir dessa nova perspectiva teórica, principalmente, quando se coloca no centro desse debate a necessidade de se discutir não apenas os seus aspectos científicos, mas, que sejamos capazes de compreender as questões sociais, ou seja, apontar alternativas para que elas sejam espaços de práticas emancipatórias e dignas. Essa questão se torna relevante a partir do momento em que se percebe que a racionalidade instrumental, como forma de conhecimento imposta pelo poder econômico, político e bélico, produziu vários déficits como já mencionados, mas, certamente, o maior deles foi promover a ausência do reconhecimento dos direitos e dos saberes de todos aqueles que constituem a sociedade.

A apresentação dessa proposta pode soar como audaciosa, no entanto, considera-se que pode acrescentar qualitativamente aos estudos críticos organizacionais no Brasil, principalmente aqueles que criticam os saberes de gestão hegemônicos difundidos nas escolas e nos espaços da prática.

As contribuições deste autor ao campo, só poderão ser avaliadas a partir do momento em 
que surgirem pesquisas empíricas que estudem as organizações a partir das categorias sociológicas apresentadas por ele.

Não é o propósito deste artigo defender o ingresso de Boaventura Santos nos estudos críticos organizacionais, porém, tão somente, mostrar a sua potencialidade uma vez que mesmo sendo europeu, as suas ideias se alinham ao pensamento latino-americano que defendem a necessidade de olhar o mundo com os próprios olhos, e, nesse caso, as organizações.

\section{REFERÊNCIAS}

ABDALLA, M. M.; FARIA, A. Em defesa da opção decolonial em administração/gestão. Cad. EBAPE. BR [online].v. 15, n. 4, p. 914-929, 2017. Disponível em: <http://dx.doi.org/10.1590/1679-395155249>. Acesso em: 3 jun. 2018

ADLER, P. S. Marx and organization studies today. In: The oxford handbook of sociology and organization studies: classical foundations. New York: Oxford University Press, 2009.

.; TURETA, C. Teoria ator-rede e estudos críticos em administração: possibilidades de um diálogo. Cadernos EBAPE (FGV), Rio de Janeiro, v. 7, n. 3, p.406-418, set. 2009.

BALLESTRIN, L. A América Latina e o giro decolonial. Revista Brasileira de Ciência Política, Brasília, n.11, p. 89-117, maio/ago. 2013.

BARCELLOS, R. M. R. DAGNELLO, E. H. L. Novas formas organizacionais: do dominante às ausências. Revista Pensamento Contemporâneo em administração, Rio de Janeiro, v. 7, n. 1, p. 1-16, jan./ mar. 2013.

BARROS, A. CARRIERI, A. O cotidiano e a história: construindo novos olhares sobre a Administração. RAE-Revista de Administração de Empresas, v. 55, n. 2, p. 151-161, 2015.
BERTERO, C. O.; CALDAS, P. M. WOOD JR., T. Produção científica em administração de empresas: provocações, insinuações e contribuições para um debate local. Revista de Administração Contemporânea, Curitiba, v. 3, n.1, jan./abr. 1999.

BURRELL, G. Ciência normal, paradigmas, metáforas, discursos e genealogia da análise. In: CLEGG, S. R.; HARDY, C.; NORD, W. R. Handbook de estudos organizacionais. São Paulo: Atlas, 2007.

COSTA, A. S. M; BARROS, D. F.; MARTINS, P. E. M. Perspectiva histórica em administração: novos objetos, novos problemas, novas abordagens. Revista de Administração de Empresas, v. 50, n. 3, p. 288-299, 2010.

DAVEL, E.; ALCADIPANI, R. Estudos críticos em administração: reflexões e constatações sobre produção brasileira. In: Encontro de Estudos Organizacionais, 2., 2002, Recife. Anais... Recife: Observatório da Realidade Organizacional: PROPAD/UFPE: Anpad, 2002.

DAVEL, E.; VERGARA, S. C. Gestão com pessoas, subjetividade e objetividade nas organizações. In:____ (Org.). Gestão com pessoas e subjetividades. São Paulo: Atlas, 2001.

DONALDSON, L. A positivist alternative to the structure-action approach. Organization Studies, v. 18, n. 1, p. 77-92, jan. 1997.

FARIA, J. H. Economia política do poder: fundamentos. Curitiba: Juruá, 2008.

- Teoria crítica em estudos organizacionais no Brasil: o estado da arte. Cadernos EBAPE.BR, v. 7, n. 3, p. 509-515, 2009.

HARVEY, D. Condição pós-moderna. Rio de Janeiro: Loyola, 2010. 
JUNCKLAUS, L. R.; BINI, T. J.; MORETO NETO, L. Independência ou Norte: reflexões sobre a influência do estrangeirismo no campo do conhecimento da administração no Brasil. Caderno Ebape, Rio de Janeiro, v. 14, n. 1, p. 47-60, jan./mar. 2016.

KOPELKE, A. L.; BOEIRA, S. L. Reflexividade e Criticidade no Ensino de Graduação em Administração. Revista Pensamento Contemporâneo em Administração, v. 10, n. 1, p. 78-95, 2016.

MACHADO, M. M. TEIXEIRA, M. L. M. Dignidade nas organizações: um olhar para além do moderno. In: Encontro de Estudos Organizacionais da Anpad - ENEO, 10., 2016, Belo Horizonte. Anais... Belo Horizonte, 2016.

MATITZ, Q. R. S.; VIZEU, F. Construção e uso de conceitos em estudos organizacionais: por uma perspectiva social e histórica. Rev. Adm. Pública [online], v. 46, n. 2, p. 577-598, 2012. Disponível em: <http://dx.doi.org/10.1590/S003476122012000200011>. Acesso em: 3 jun. 2018.

MEDEIROS, A. L.; TEIXEIRA, M. L. M. Limites da Dignidade dos docentes nas práticas de gestão em universidades brasileiras. Revista GUAL, Florianópolis, v. 10, n. 1, p. 134-154, maio. 2017.

MENEGHETTI, F.; FARIA, J. H. Gestão e reificação dos homens do mar. Revista de Administração Mackenzie, v. 13, n. 4, p. 15-47, 2012.

MIZOCZKI, M. C. Das práticas não gerenciais de organizar à organização para a práxis da libertação. In: MIZOCZKI, M. C.; FLORES, R.; MORAES, J. (Org.). Organização e práxis libertadora. Porto Alegre: Dacasa, 2010.

MISOCZKY, M. C; ANDRADE, J. A. de. Tréplica: quem tem medo do fazer acadêmico como práxis? Revista de Administração Contemporânea, v. 9, n. 1, p. 239-245, jan./mar. 2005.
MORIN, E. Introdução ao pensamento complexo. 4. ed. Porto Alegre: Sulina, 2011.

MOZATTO, A. R.; GRZYBOVSKI, D. Análise crítica nos estudos organizacionais: concepção de indivíduo sob a perspectiva emancipatória. Cadernos EBAPE.BR, v. 11, n. 4, p. 503-519, 2013.

MOTTA, F. C. Cultura e organizações no Brasil. In: MOTTA, F. C.; CALDAS, M. Cultura organizacional e cultura brasileira. São Paulo: Atlas, 2014.

PAES, K. D.; DELLAGNELO, E. H. L. Boaventura de Sousa Santos e Guerreiro Ramos: um olhar crítico sobre as ausências e emergências em organizações. In: Encontro Nacional da Anpad - EnANPAD, 36., 2012, Rio de Janeiro. Anais... Rio de Janeiro: ANPAD., 2012a.

;____. Um diálogo entre Boaventura de Sousa Santos e Milton Santos: por um outro olhar a produção do social. In: Encontro de Estudos Organizacionais da Anpad - ENEO, 7., 2012, Curitiba. Anais... Curitiba: ENEO, 2012 b.

PAES DE PAULA, A. P; ALCADIPANI, R. Apresentação - Fórum Estudos Críticos em Administração. RAE-eletrônica, v. 3, n. 2, 2004. Disponível em: http://www16.fgv.br/rae/ eletrônica/ index. Acesso em 10 de Maio de 2018

PAES DE PAULA, A. P. Guerreiro Ramos: resgatando o pensamento de um sociólogo crítico das organizações. Organizações \& Sociedade, v.14, n. 40, p.169-188, mar. 2007.

; MARANHÃO, C. M. S. A.; BARROS, A. N. Pluralismo, pós-estruturalismo e "gerencialismo engajado": os limites do movimento critical management studies. Cadernos EBAPE.BR, v. 7, n. 3, p. 393-404, 2009.

RODRIGUES, S. B; CARRIERI, A. de P. A tradição anglo-saxônica nos estudos organizacionais brasileiros. Revista de Administração Contemporânea, Curitiba, v. 5, número especial, p. 81-102, 2001. 
ROSA, A. R.; ALCADIPANI, R. A terceira margem do rio dos estudos críticos sobre administração e organizações no Brasil: (re)pensando a crítica a partir do pós-colonialismo. Revista de Administração do Mackenzie, São Paulo, v.14, n. 6, p. 185-215, nov./ dez. 2013.

SANTOS, B. S. Um discurso sobre as ciências. 7. ed. Porto: Edições Afrontamento, 1995.

A universidade no século XXI: para uma reforma democrática e emancipatória da universidade. Educação, Sociedade \& Culturas, n. 23, 2005a.

Os processos da globalização. In:

(Org.). Globalização: fatalidade ou utopia? 3. ed. Porto Alegre: Edições Afrontamento, 2005b.

Renovar a teoria crítica e reinventar a emancipação social. São Paulo: Boitempo, 2007.

A crítica da razão indolente: contra 0 desperdício da experiência. 7. ed. São Paulo: Cortez, 2009.

. A gramática do tempo: uma nova cultura política. 3. ed. São Paulo: Cortez, 2010a.

Introdução a uma ciência pós-moderna.

5. ed. São Paulo: Edições Graal, 2010b.

.; MENESES, M. P. (Org.). Epistemologias

do Sul. São Paulo: Cortez, 2010c.

SCHLICKMANN, R.; MELO, P. A. A influência das correntes do pensamento científico na concepção dos paradigmas funcionalista e crítico da administração. In: Encontro de Ensino e de Pesquisa em Administração e Contabilidade, 2., 2009, Curitiba. Anais... Curitiba, 2009.

SERVA, M. A. O surgimento e o desenvolvimento da epistemologia da administração: inferências sobre a contribuição ao aperfeiçoamento da teoria administrativa. Revista Gestão Organizacional, Chapecó, v. 6, n. 3, p. 50-64, 2013.
. Epistemologia da administração no Brasil: o estado da arte. Cadernos EBAPE.BR, Rio de Janeiro, v. 15, n. 4, out./dez. 2017. Disponível em: <http:// dx.doi.org/10.1590/1679-395173209>. Acesso em: 3 jun. 2018.

SOUZA, E. M. Pós-modernidade nos estudos organizacionais: equívocos, antagonismos e dilemas. Cadernos EBAPE.BR, Rio de Janeiro, v. 10, n. 2, Junho 2012.

SOUZA, C. da S. O conhecimento em administração: uma cartografia das perspectivas epistemológicas. 2016. 185f. Tese (Doutorado em Ciências Sociais) - Centro de Ciências Humanas, Letras e Artes, Universidade Federal do Rio Grande do Norte, Natal, 2016.

STENGERS, I. A invenção das ciências modernas. São Paulo: Editora 34, 2002.

VIZEU, F. Potencialidades da análise histórica nos estudos organizacionais brasileiros. Revista de Administração de Empresas, v. 50, n. 1, p. 37-47, 2010.

WANDERLEY, S.; BARROS, A. Decoloniality, geopolitics of knowledge and historic turn: towards a Latin American agenda. Management \& Organizational History, 2018. Disponível em: <https://doi.org/10.1080/17449359.2018.1431551> . Acesso em 3 jun. 2018.

WENGER, E. Comunidades de prácticas: aprendizaje, significado e identidad. Cambridge, UK: Edição Paidós, SAICF, 2001.

WOOD JR., T.; TONELli, M. J. COOKE, B. Colonização e neocolonização da gestão de recursos humanos no Brasil (1950-2010). Revista de Administração de Empresas, v. 51, n.3, p. 232-243, maio/jun. 2011. 